\title{
Hepatitis C Virus-Related Lymphomagenesis in a Mouse Model
}

\author{
Kyoko Tsukiyama-Kohara, ${ }^{1}$ Satoshi Sekiguchi, ${ }^{2}$ Yuri Kasama, ${ }^{1}$ \\ Nagla Elwy Salem, ${ }^{1,3,4}$ Keigo Machida, ${ }^{5}$ and Michinori Kohara ${ }^{2}$ \\ ${ }^{1}$ Department of Experimental Phylaxiology, Faculty of Life Sciences, Kumamoto University, 1-1-1 Honjo, Kumamoto-shi, \\ Kumamoto 860-8556, Japan \\ ${ }^{2}$ Department of Microbiology and Cell Biology, The Tokyo Metropolitan Institute of Medical Science, 2-1-6 Kamikitazawa, Setagaya-ku, \\ Tokyo 156-8506, Japan \\ ${ }^{3}$ Department of Medical Virology, Faculty of Life Sciences, Kumamoto University, 1-1-1 Honjo, Kumamoto-shi, \\ Kumamoto 860-8556, Japan \\ ${ }^{4}$ Clinical Pathology Department, Faculty of Medicine, Suez Canal University, Round Road Kilo 4.5, Ismailia, Egypt \\ ${ }^{5}$ Department of Molecular Microbiology and Immunology, University of Southern California, Keck School of Medicine, Los Angeles, \\ CA 90033, USA
}

Correspondence should be addressed to Kyoko Tsukiyama-Kohara, kkohara@kumamoto-u.ac.jp

Received 5 May 2011; Accepted 2 June 2011

Academic Editors: D. Efremov and L. Visser

Copyright (C) 2011 Kyoko Tsukiyama-Kohara et al. This is an open access article distributed under the Creative Commons Attribution License, which permits unrestricted use, distribution, and reproduction in any medium, provided the original work is properly cited.

B cell non-Hodgkin lymphoma is a typical extrahepatic manifestation frequently associated with hepatitis C virus (HCV) infection. The mechanism by which HCV infection leads to lymphoproliferative disorder remains unclear. Our group established HCV transgenic mice that expressed the full HCV genome in B cells (RzCD19Cre mice). We observed a 25.0\% incidence of diffuse large B cell non-Hodgkin lymphomas (22.2\% in male and $29.6 \%$ in female mice) within 600 days of birth. Interestingly, RzCD19Cre mice with substantially elevated serum-soluble interleukin-2 receptor $\alpha$-subunit (sIL-2R $\alpha$ ) levels (>1000 pg/mL) developed B cell lymphomas. Another mouse model of lymphoproliferative disorder was established by persistent expression of HCV structural proteins through disruption of interferon regulatory factor-1 (irf- $1^{-/} / \mathrm{CN} 2$ mice). Irf $-1^{-/} / \mathrm{CN} 2$ mice showed extremely high incidences of lymphomas and lymphoproliferative disorders. Moreover, these mice showed increased levels of interleukin (IL)-2, IL-10, and Bcl-2 as well as increased Bcl-2 expression, which promoted oncogenic transformation of lymphocytes.

\section{Introduction}

The incidence of non-Hodgkin lymphoma (NHL) is rising worldwide and is higher in developed countries than in Africa and Asia [1]. B cell non-Hodgkin lymphoma is a typical extrahepatic manifestation frequently associated with hepatitis $\mathrm{C}$ virus (HCV) infection [2]. The prevalence of $\mathrm{HCV}$ infection in patients with B cell non-Hodgkin lymphoma is approximately $15 \%$ [3]. The HCV envelope protein E2 binds human CD81 [4], a tetraspanin expressed on various types of cells, including lymphocytes, and activates $B$ cell proliferation [5]. Infection and replication of $\mathrm{HCV}$ were observed in B cells $[6,7]$ although the direct effects, particularly in vivo, have not been clarified. To determine the direct effect of HCV infection on B cells in vivo, we crossed transgenic mice with an integrated full-length HCV genome $(\mathrm{Rz})$ under the conditional Cre/loxP expression system, with mice expressing the Cre enzyme [8] under transcriptional control of the B lineage-restricted gene CD19 [9].

To investigate the mechanism of development of lymphoproliferation or B cell non-Hodgkin lymphoma in HCV patients, we also developed a transgenic mouse model that conditionally expressed HCV cDNA (nucleotides 294-3435), including the viral genes that encode the core, E1, E2, and NS2 proteins, by using the Cre/loxP system (in core-NS2 [CN2] mice) $[10,11]$. Conditional transgene activation of the $\mathrm{HCV}$ cDNA (core, E1, E2, and NS2) protects mice from Fas-mediated lethal acute liver failure, by inhibiting cytochrome $c$ release from mitochondria [11]. Persistent $\mathrm{HCV}$ protein expression is established by targeted disruption 
of interferon regulatory factor-1 (irf-1), and high incidences of lymphoproliferative disorders are noted in irf-1 $1^{-/-} \mathrm{CN} 2$ mice [12].

Previously, transgenic mice that expressed the HCV core protein were established using a promoter derived from hepatitis B virus [13], whereas mice that expressed structural or complete viral proteins were established using promoters derived from the albumin gene [14]. These mice were immunotolerant to the transgene and did not develop hepatic inflammation. However, they developed age-related hepatic steatosis and hepatocellular carcinomas. In contrast, the CN2 mice used in the present study were not immunotolerant to the $H C V$ gene and developed hepatitis after the onset of $\mathrm{HCV}$ gene expression. However, the expression of $\mathrm{HCV}$ in these mice was usually lost after 21 days. Therefore, an animal model of persistent $\mathrm{HCV}$ protein expression is required for examining the effects of chronic HCV infection in vivo.

IFN signaling mediates tumor-suppressor effects and antiviral responses and is regulated by key transcription factors of the interferon-regulatory factor (IRF) protein family, including IRF1, IRF2, IRF3, IRF7, and IRF9. Targeted disruption of irf-1 results in aberrant lymphocyte development and a marked reduction in the number of $\mathrm{CD} 8^{+} \mathrm{T}$ cells in the peripheral blood, spleen, and lymph nodes [15]. In addition, natural killer cell development is impaired in irf-1 $1^{-/-}$mice [16]. The mechanisms by which HCV infection induces IFN resistance and influences the development of lymphomas are poorly understood. Therefore, we established an $\mathrm{irf-1^{-/- }}$ CN2 mouse model of persistent $\mathrm{HCV}$ expression, which allowed us to investigate the effects of HCV on lymphatic tissue tumor development.

\section{Spontaneous Development of B Cell Lymphomas in the RzCD19Cre Mouse}

The full-genome HCV expression was induced by the Cre/ loxP system with CD19Cre (Figure 1(A)). Expression of $\mathrm{HCV}$ was mainly induced in B cells (Figure 1(B)). The incidence of B cell lymphomas in RzCD19Cre mice was $25.0 \%$ (22.2\% in male and $29.6 \%$ in female mice) and was significantly higher than the incidence in the HCV-negative groups. Lymphomas were diagnosed as typical diffuse B cell non-Hodgkin lymphomas. Most were CD45R positive and located in the mesenteric lymph nodes (Figure $1(\mathrm{C})$ ). Some were identified as intrahepatic lymphomas (incidence, $4.2 \%)$. HCV expression was detected in all B cell lymphomas of RzCD19Cre mice. Indeed, the expression of the $\mathrm{HCV}$ or $\mathrm{HCV}$ proteins induces the spontaneous development of B cell lymphomas, irrespective of the integrated site in the mouse genome.

Serum concentrations of IL- $1 \alpha$, IL- $1 \beta$, IL-2, IL-3, IL-4, IL-5, IL-6, IL-9, IL-10, IL-12(p40), IL-12(p70), IL-13, IL-17, eotaxin, G-CSF, GM-CSF, IFN- $\gamma$, KC, MCP- 1 , MIP- $1 \alpha$, MIP$1 \beta$, RANTES, TNF- $\alpha$, IL-15, FGF-basic, LIF, M-CSF, MIG, MIP-2, PDGF $\beta$, VEGF, alanine aminotransferase (ALT), and aspartate aminotransferase (AST) were not significantly different in the presence or absence of B cell lymphomas. Interestingly, the average sIL-2R $\alpha$ level was significantly higher in the sera from RzCD19Cre mice with B cell lymphomas $(830.3 \pm 533.0 \mathrm{pg} / \mathrm{mL})$ than in that from tumor-free control groups, including the RzCD19Cre, Rz, CD19Cre, and wild-type (WT) mice $(499.9 \pm 110.2 \mathrm{pg} / \mathrm{mL} ; P<0.0057)$ (Figure $1(\mathrm{D})$ ). The difference in the average sIL-2R $\alpha$ levels between the sera from groups with tumors other than B cell lymphomas $(430.46 \pm 141.15 \mathrm{pg} / \mathrm{mL})$ and that from tumorfree control groups was insignificant $(P>0.05)$. Moreover, all $\mathrm{RzCD} 19 \mathrm{Cre}$ mice with a relatively high level of sIL-2R $\alpha$ ( $>1000 \mathrm{pg} / \mathrm{mL}$ ) presented with B cell lymphomas. A significant increase in sIL-2R $\alpha$ was also observed in MxCre/CN2-29 mice that expressed the HCV CN2 gene [8] and had B cell lymphomas, compared with tumor-free control (CN2-29) mice.

To examine whether sIL-2R $\alpha$ was derived from lymphoma tissues, we quantified IL-2R $\alpha$ concentrations in splenocytes, peripheral blood lymphocytes (PBLs), and B cell lymphoma tissues. The concentration of IL-2R $\alpha$ was significantly higher in splenocytes from RzCD19Cre mice than in splenocytes from CD19Cre mice. Moreover, the concentration of IL-2R $\alpha$ in B cell lymphoma tissues from RzCD19Cre mice was higher than that in splenocytes [8]. These results strongly suggest that B cell lymphomas directly contribute to the elevated serum concentrations of sIL$2 \mathrm{R} \alpha$ in RzCD19Cre mice. They also strongly support the possibility that persistent expression of $\mathrm{HCV}$ could directly induce transformation of B cells.

\section{Persistent HCV Expression and Lymphoproliferative Disorder}

RzCD19Cre mice are immunotolerant to HCV, because $H C V$ is expressed in B cells before birth. In contrast, $\mathrm{CN} 2$ mice express $H C V$ after they are administered the recombinant adenovirus that expresses the Cre enzyme (Figures 2(a) and 2(b)). The expression of HCV in these mice is usually lost after 21 days (Figure 2(b)) through removal of HCV-expressing hepatocytes by the immune response. To establish persistent HCV expression, we disrupted irf-1 by crossing of RzCD19Cre mice with $\operatorname{irf}-1^{-/-}$mice. IRF-1 plays a significant role in the Th1-type immune response and its absence is expected to decrease the elimination of $\mathrm{HCV}$-expressing cells. As expected, HCV expression in $i r f-1^{-/-}$CN2 mice persisted for more than 500 days (Figure 2(c)).

A significant percentage of the mice that expressed the $\mathrm{HCV}$ core protein (irf-1 $1^{-1-} \mathrm{CN} 2$ mice) showed polyclonal lymphoid growth disturbances, including splenomegaly, expanded lymph nodes, adenocarcinoma in the abdomen or leg, and lymphoma of the liver or Peyer's patches (Figures 2(d) and 2(e)). In contrast, hepatocytes with abundant expression of HCV proteins rarely developed into hepatocellular carcinomas. Hematoxylin and eosin (H\&E) staining of splenomegalic tissue showed extensive hyperplasia of the white pulp zones, in which the cortical zones contained lymphoid follicles and scattered germinal centers although mitotic figures were rarely observed. These results indicate that persistent expression of HCV proteins frequently induces lymphoproliferative disorders in addition to liver 

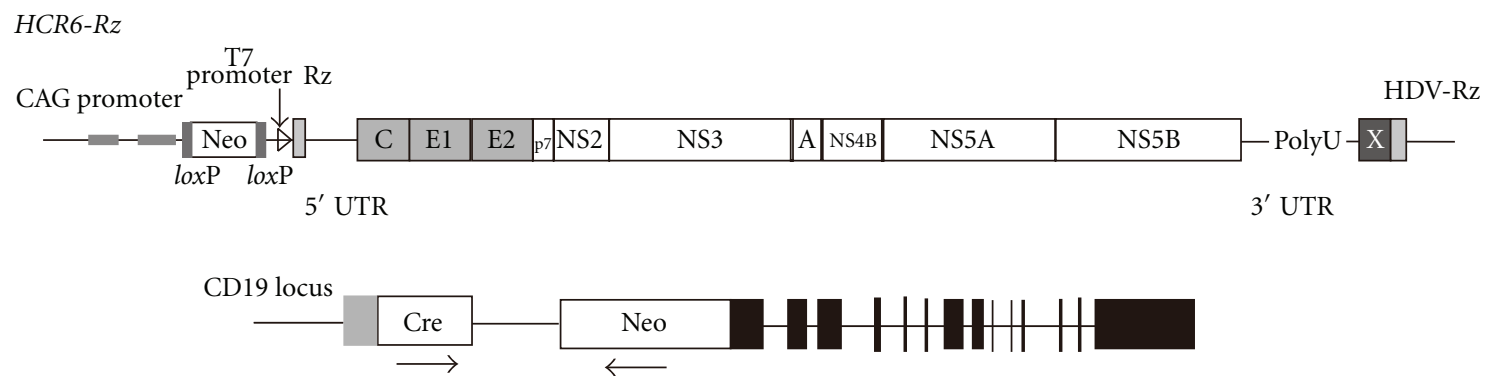

(A)

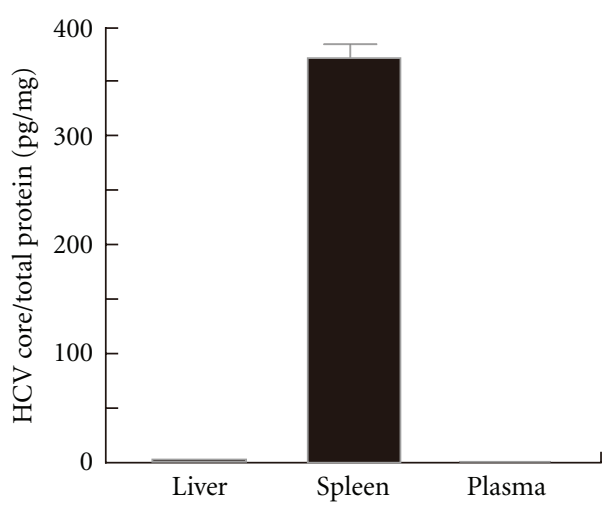

(B)

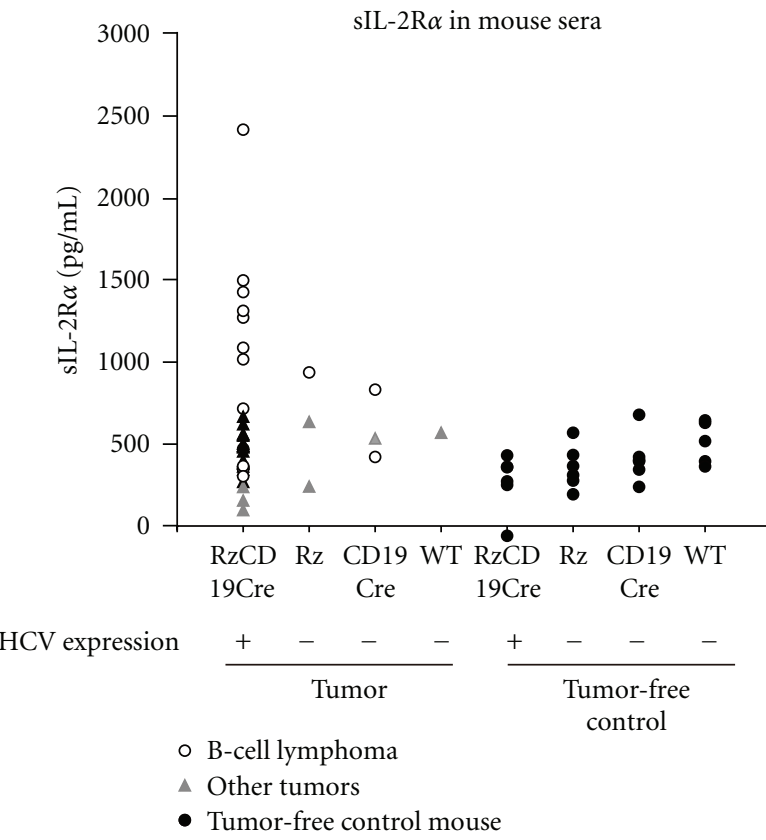

(D)

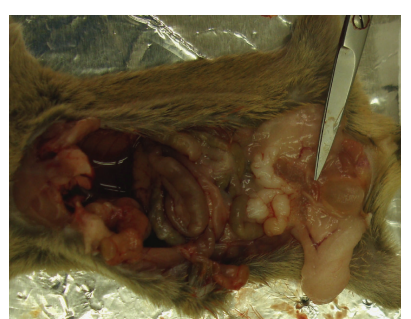

(a)

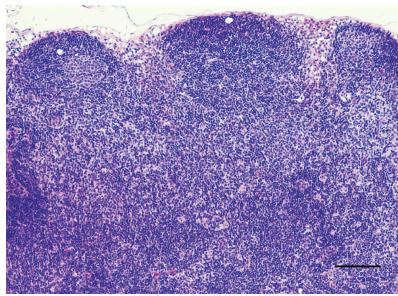

(c)

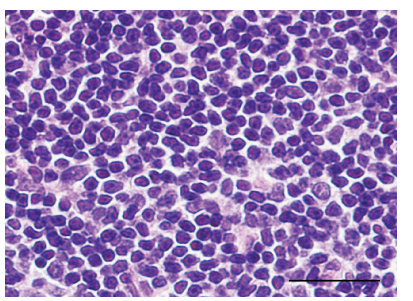

(e)

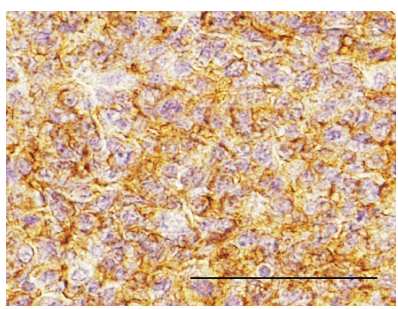

(g)

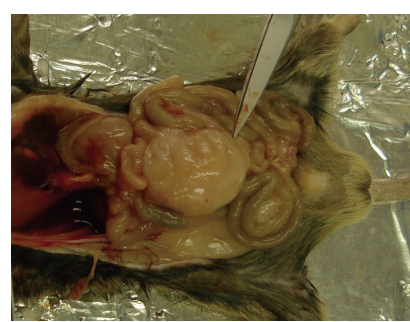

(b)

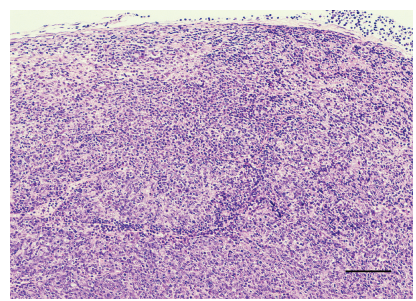

(d)

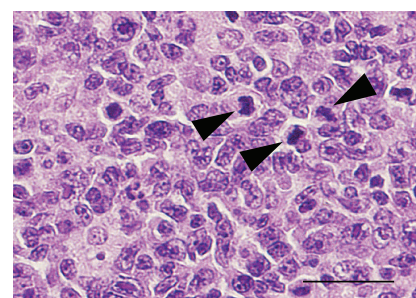

(f)

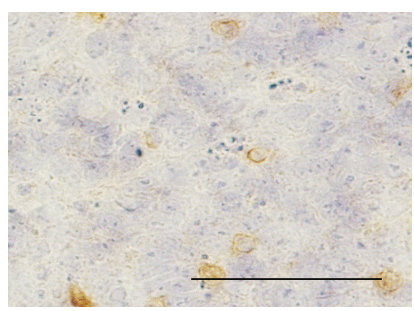

(h)

(C)

Figure 1: (A) The structure of the hepatitis $\mathrm{C}$ virus (HCV) transgene (HCR6-Rz); HCV gene expression was regulated by the Cre/lox $\mathrm{P}$ expression cassette (upper). The Cre transgene was located in the CD19 locus (bottom). (B) Expression of HCV core protein in the liver, spleen, and plasma of RzCD19Cre mice was quantified by core ELISA. Data represent the mean $(\mathrm{SD})(n=3)$. (C) Histological analysis of tissues from a normal mouse ( $\mathrm{a}, \mathrm{c}$, e; lymph node from CD19Cre mouse; b, d, f) and B cell lymphoma (b, d, f; RzCD19Cre mouse). Paraformaldehyde-fixed and paraffin-embedded tumor tissues were stained with hematoxylin and eosin (H\&E) (c-f); immunostaining of lymphoma with anti-CD45R (g) and anti-CD3 (h) is indicated. Scale bars, $100 \mu \mathrm{m} \mathrm{(c,} \mathrm{d)} \mathrm{and} 20 \mu \mathrm{m}(\mathrm{g}, \mathrm{h})$; arrow heads indicate mitotic cells. (D) Concentration of sIL-2R $\alpha$ in serum samples from tumor-free control mice, and RzCD19Cre and wild-type (WT) mice with or without B-cell lymphomas or other tumors. 
CN2

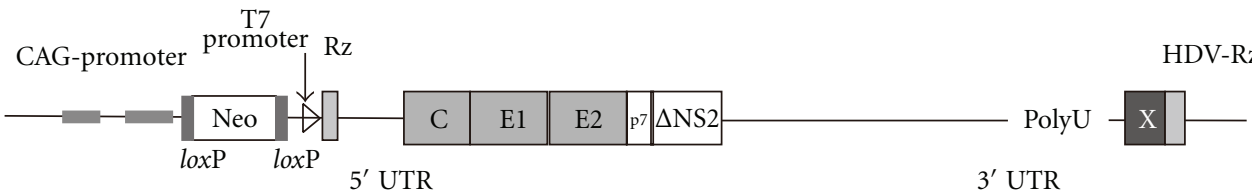

(a)

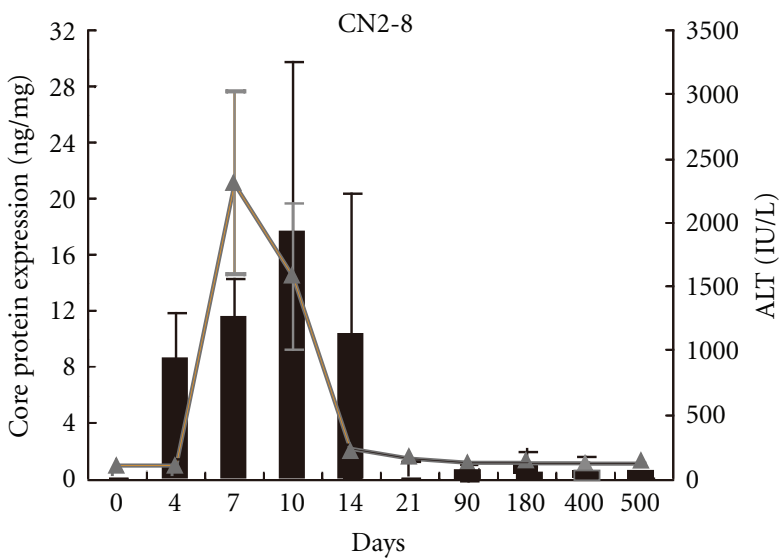

Core

$\triangle$ ALT

(b)
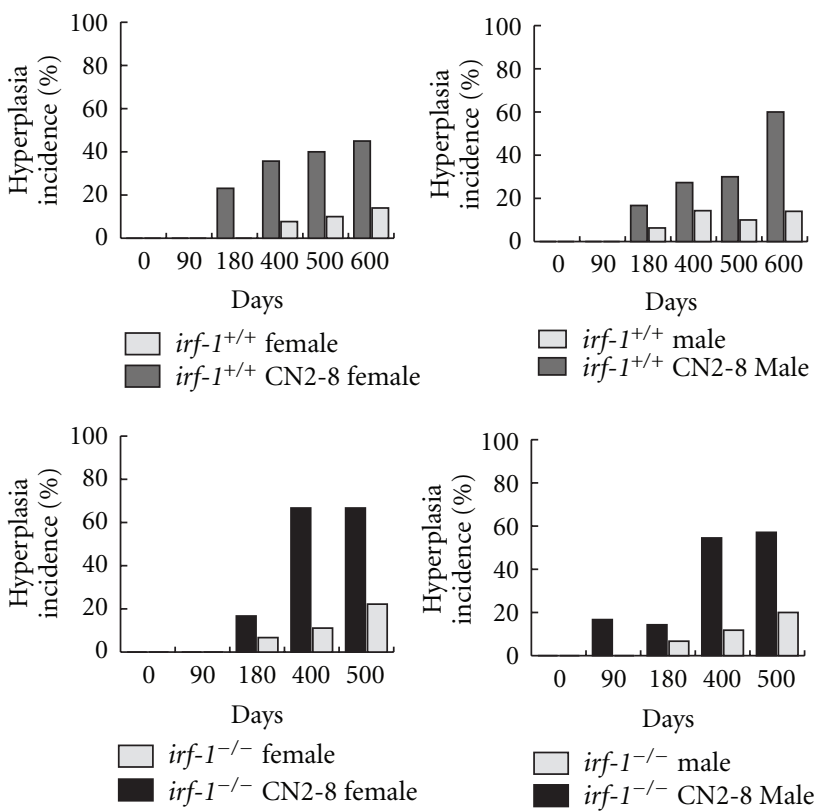

(d)

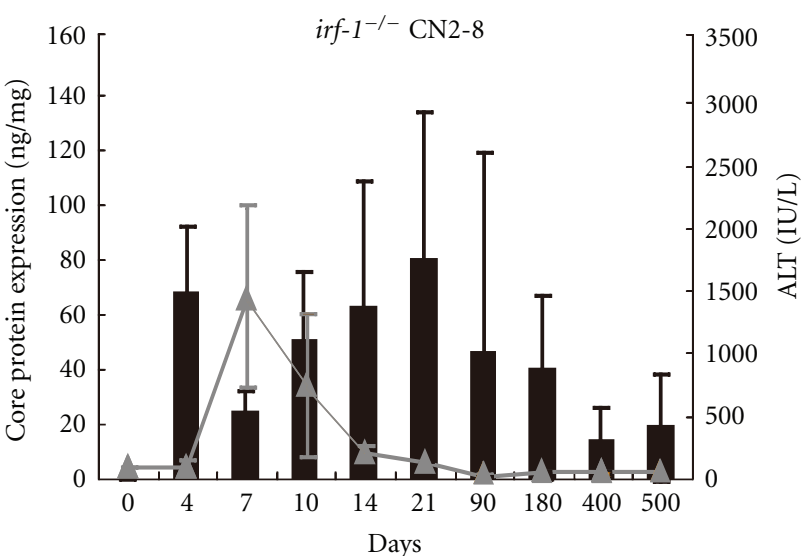

Core

$\triangle$ ALT

(c)

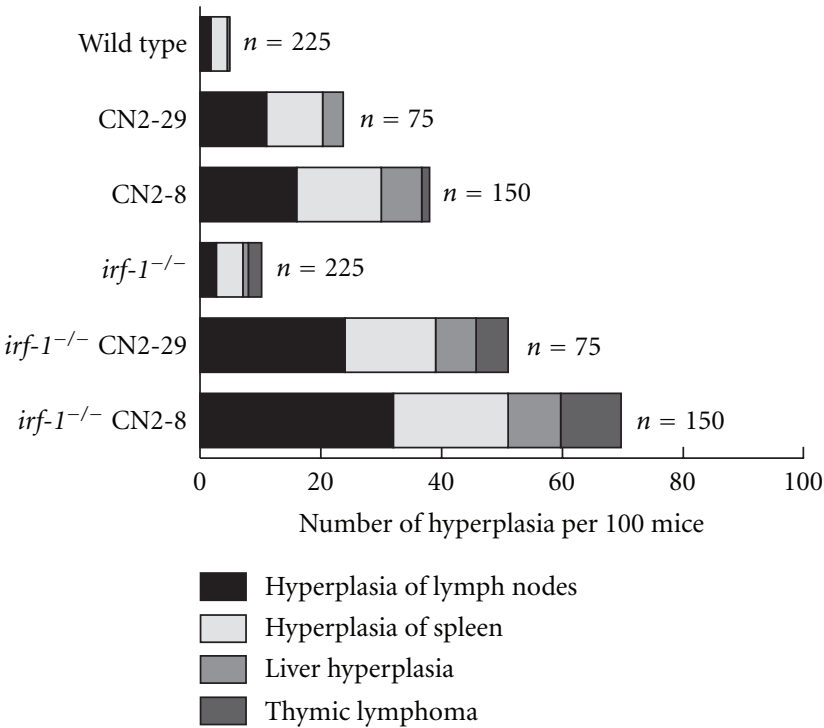

(e)

Figure 2: (a) The structure of the HCV transgene (core-NS2); gene expression was regulated by the Cre/loxP expression cassette. (b) and (c) Serum alanine aminotransferase (ALT) levels and core protein expression ELISA system in hepatocytes from CN2-8 (b) and irf-1 ${ }^{-1-}$ CN2-8 (c) mice after administration of AxCANCre $\left(n=225\right.$ for $i r f-1^{-/-}, n=75$ for $i r f-1^{-1-}$ CN2-29, $n=150$ for irf-1 $1^{-/-}$CN2-8, $n=225$ for wild type, $n=75$ for CN2-29, and $n=150$ for CN2-8; total $n=900$ ). (d) HCV protein expression enhanced hyperplasia in male and female CN2 and irf-1 $1^{-1-}$ CN2 mice. The occurrence of hyperplasia was monitored every 7 days for 600 days after administration of AxCANCre. (e) Histological analysis of spontaneous proliferative disturbances in CN2 transgenic mice. Of the 900 mice injected with AxCANCre, 25 of 75 (33\%) CN2-29, 47 of 150 (31\%) CN2-8, 29 of 75 (39\%) irf-1 $1^{-/-}$CN2-29, and 62 of 150 (41\%) irf-1 ${ }^{-/-}$CN2-8 mice developed proliferative disturbances. 


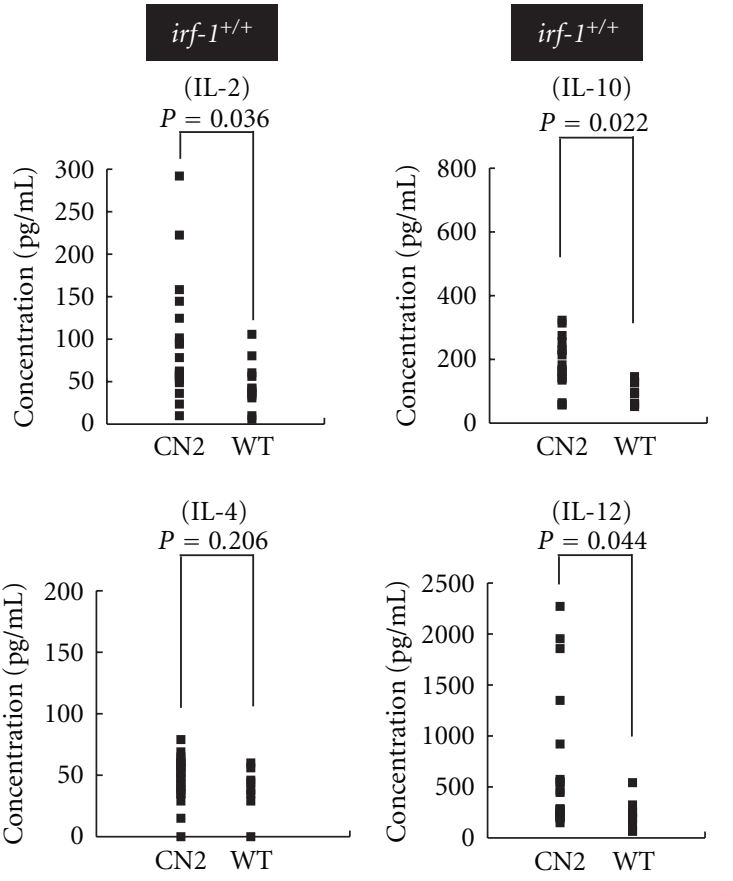

(a)
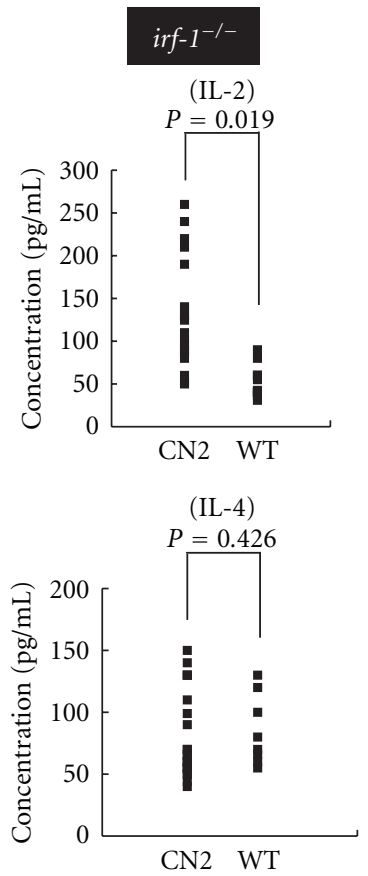

(b)
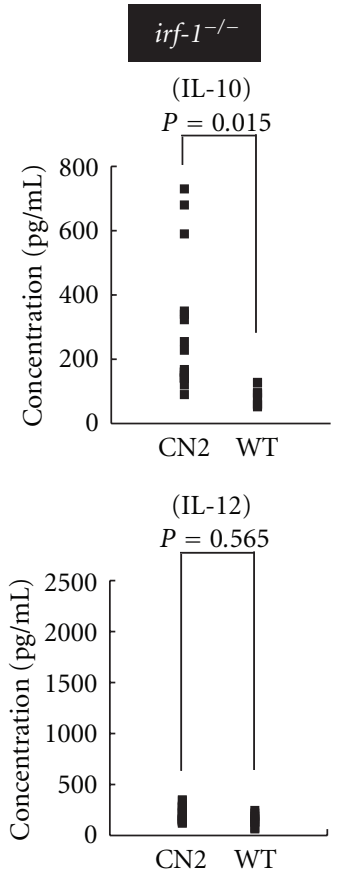

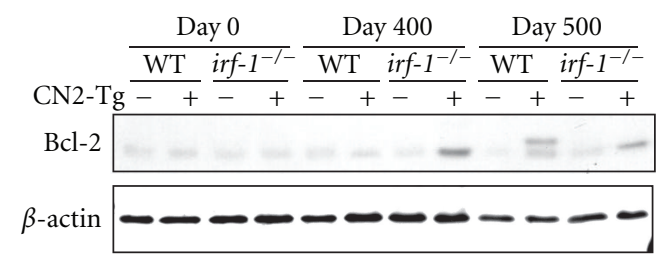

(c)

Figure 3: (a) Serum IL-2, IL-4, IL-10, and IL-12 levels in $i r f-1^{+/+}$CN2 (Tg+) and irf- $1^{+/+}$WT mice measured by ELISA. $P$ values $<0.05$ were considered significant. (b) Serum IL-2, IL-4, IL-10, and IL-12 levels in irf-1 $1^{-/-}$CN2 (Tg+) and irf-1 $1^{-/-}$WT mice measured by ELISA. $P$ values are based on the mean cytokine concentrations. (c) Bcl-2 protein levels in the lymph nodes of $\operatorname{irf-1^{+/+}}$ WT and $\operatorname{irf}-1^{-/-}$WT or transgenic (CN2-29) mice on day 0, day 400, and day 500 after administration of AxCANCre. Bcl-2 migrated at $26 \mathrm{kD}$.

hyperplasia, which is consistent with the phenotype of patients with hepatocellular carcinoma.

The average ratio of $\mathrm{T}$ cells to $\mathrm{B}$ cells in the lymph nodes and spleens of CN2 mice was significantly higher than that in WT mice. The majority of $\mathrm{CD}^{+}$lymphocytes and a few $\mathrm{CD}^{+}$lymphocytes expressed CD4 on their surfaces. The proliferating cells were mainly $\mathrm{CD} 4^{+} \mathrm{T}$ cells although some were $\mathrm{CD} 45 \mathrm{R}^{+} \mathrm{B}$ cells. The irf-1 ${ }^{-1-} \mathrm{CN} 2$ mice also developed B cell lymphomas (data not shown). These results confirm that HCV protein expression induces lymphoproliferative disorders that involve excessive expansion of both $\mathrm{T}$ cells and $\mathrm{B}$ cells. The cell population that showed negative results for $\mathrm{T}$ cell receptor ( $\alpha, \beta, \gamma$, and $\delta$ isoforms) staining was smaller in irf- $1^{-/-} \mathrm{CN} 2$ mice than that in the other mice.

The disruption of irf-1 inhibited Fas-induced apoptosis, presumably by decreasing the levels of caspase- 6 and caspase7 messenger RNA. These results suggest that the reduced expression of effector caspases delays Fas-mediated apoptosis in $i r f-1^{-/-}$mice and prevents the elimination of HCV-expressing cells in vivo.
The CN2 mice showed significantly increased levels of serum IL-2, IL-10, and IL-12 (Figure 3(a)). Notably, the CN2 mice with proliferative disturbances in the lymph nodes and spleen had dramatically elevated levels of these cytokines, suggesting that altered cytokine production is involved in aberrant lymphocyte proliferation or differentiation. In contrast, the $\mathrm{irf}-1^{-1-} \mathrm{CN} 2$ mice did not show elevated levels of serum IL-12, but had significantly higher levels of serum IL2 and IL-10 than did $\operatorname{irf-1^{-1-}}$ mice (Figure 3(b)). Thus, the disruption of irf-1 negated the increase in the IL-12 level, but augmented the increases in the levels of IL-2 and IL-10 in CN2 mice. These results indicate that IL-2 and IL-10 play key roles in the induction of the lymphoproliferative phenotype

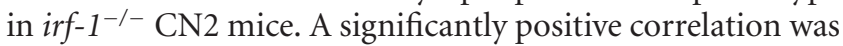
found between the cytokine levels and spleen weights of $C N 2$ gene-expressing mice with the $i r f-1^{+/+}$background $(R=$ $0.43, P<0.05$, and $R=0.53, P<0.05$, resp.). These results indicate that IL-2 and IL-10 are involved in lymphoproliferation in viral protein-expressing mice.

$\mathrm{Bcl}-2$ is an integral inner mitochondrial membrane protein, overexpression of which blocks the apoptotic death 
TABLE 1: Synergistic effects of cytokines on Fas-induced apoptosis in irf-1 ${ }^{-/-} \mathrm{CN} 2$ mice.

\begin{tabular}{|c|c|c|c|c|}
\hline & None & IL-2 + IL-10 & IL-2 + IL-12 & IL-10 + IL-12 \\
\hline \multicolumn{5}{|c|}{ WT mice } \\
\hline Bcl-2 fold increase & - & - & - & - \\
\hline Annexin $\mathrm{V}+$ percentage & $* * * *$ & $* * * *$ & $* * * *$ & $* * * *$ \\
\hline Caspase-9 & $* *$ & $* *$ & $* *$ & $* *$ \\
\hline Caspase-3/7 & $* * *$ & $* * *$ & $* * *$ & $* * *$ \\
\hline \multicolumn{5}{|c|}{ irf-1 $1^{-/-}$mice } \\
\hline Bcl-2 fold increase & - & - & - & - \\
\hline Annexin $\mathrm{V}+$ percentage & $* * *$ & $* * *$ & $* * *$ & $* * *$ \\
\hline Caspase-9 & $* *$ & $* *$ & $* *$ & $* *$ \\
\hline Caspase-3/7 & $* *$ & $* *$ & $* *$ & $* *$ \\
\hline \multicolumn{5}{|c|}{ CN2-29 mice } \\
\hline Bcl-2 fold increase & - & + & - & - \\
\hline Annexin $\mathrm{V}+$ percentage & $* * *$ & $* *$ & $* * *$ & $* * *$ \\
\hline Caspase- 9 & $* *$ & $*$ & $*$ & $* *$ \\
\hline Caspase-3/7 & $* *$ & * & $*$ & $*$ \\
\hline \multicolumn{5}{|c|}{ irf-1-1- CN2-29 mice } \\
\hline Bcl-2 fold increase & + & +++ & ++ & ++ \\
\hline Annexin $\mathrm{V}+$ percentage & $* *$ & - & $*$ & $*$ \\
\hline Caspase-9 & $* *$ & - & $*$ & $*$ \\
\hline Caspase- $3 / 7$ & $*$ & - & $*$ & $*$ \\
\hline
\end{tabular}

Bcl-2: -, less than 2-fold increase; +, more than 2-fold increase; ++, more than 4-fold increase; +++, more than 6-fold increase (in comparison with mock treatment).

Annexin V: -, less than $20 \%$ decrease; *, up to $20 \%$ decrease; **, up to $40 \%$ decrease; ***, up to $60 \%$ decrease; ****, more than $60 \%$ decrease (in comparison with mock treatment).

Caspase-9: -, less than 10 -fold decrease; *, up to 50 -fold decrease; **, up to 200 -fold decrease; ***, up to 400 -fold decrease; ****, more than 400 -fold decrease (in comparison with mock treatment).

Caspase-3/7: -, less than 200 -fold decrease; $*$, up to 500 -fold decrease; ${ }^{* *}$, up to 1000 -fold decrease; ${ }^{* *}$, more than 1000 -fold decrease (in comparison with mock treatment).

of pro-B-lymphocyte death [17]. Bcl-2 transgene expression increases the oncogenic potential [18] and is linked with B cell neoplasm and $t(14 ; 18)$ translocation [19]. We therefore examined the level of $\mathrm{Bcl}-2$ protein and found that it was upregulated in the lymph nodes of $i r f-1^{-/-}$CN2 mice after 400 days (Figure 3(c)).

IL-10 treatment in the presence of IL-2 greatly inhibited Fas-induced apoptosis in irf-1 $1^{-1-} \mathrm{CN} 2$ mice compared with other groups (Table 1). Furthermore, irf-1 disruption accelerated the resistance of splenocytes to Fas-induced apoptosis in the presence of IL-2, IL-10, and/or IL-12. In particular, IL-2 plus IL-10 treatment produced the strongest upregulation of the Bcl-2 mRNA levels in splenocytes of $\mathrm{irf}-1^{-1-}$ CN2 mice. This indicates that IL-2, IL-10, and/or IL-12 contribute to upregulation of $b c l-2$ expression, which subsequently inhibits Fas-induced apoptosis. Caspase- 9 and caspase-3/7 activities were inversely correlated with the level of $b c l-2$ expression. These results indicate that aberrant cytokine expression and disruption of IFN signaling affect $b c l-2$ expression synergizing with $\mathrm{HCV}$ proteins, which is associated with the inhibition of caspase expression.
TABLE 2: Synergistic effects of cytokines on Bcl-2 expression in WT and $i r f-1^{-/}$mice in the presence of HCV core protein.

\begin{tabular}{lcc}
\hline & WT mice & irf-1 - $^{-1}$ mice \\
\hline Mock & - & - \\
IL-2 + IL-10 & + & +++ \\
IL-2 + IL-12 & + & ++ \\
IL-10 + IL-12 & + & ++ \\
IL-2 & - & - \\
IL-10 & + & ++ \\
IL-12 & - & - \\
IL-2 + Il-10 + IL-12 & - & + \\
\hline
\end{tabular}

Bcl-2: - , less than 2-fold increase; + , more than 2-fold increase; ++ , more than 4 -fold increase; +++ , more than 5 -fold increase (in comparison with mock treatment).

HCV core protein induced IL-2 and IL-10. Envelope protein E2 induced IL-12 expression. These results indicate that the HCV core and E2 proteins are responsible for IL-2, IL-10, and IL-12 expression. Core protein expression and IL-10 stimulation most strongly induced Bcl-2 expression 
(Table 2). From these results, core protein contributes significantly to the induction of Bcl-2 in the presence of cytokines.

\section{Conclusion}

Our results show that the conditional expression of HCV proteins induces inflammation and lymphoproliferative disorders. Furthermore, established animal models will probably provide critical information for the elucidation of the molecular mechanism(s) underlying the spontaneous development of B cell non-Hodgkin lymphoma after HCV infection. The disruption of irf-1 enhances lymphoproliferative disorders. Therefore, IRF-1-inducible genes probably play essential roles in suppressing $\mathrm{HCV}$-induced lymphoma and in eliminating HCV protein-expressing cells. The overexpression of apoptosis-related proteins (including Bcl-2) and/or aberrant cytokine production are the primary events in HCV-induced lymphoproliferation.

The HCV gene has the potential to induce B cell lymphomas in RzCD19Cre mice, without inducing host immune responses against $H C V$ gene product. This is in agreement with the results of a previous study, which indicate that viral elimination reduces the incidence of malignant lymphoma in patients infected with HCV [20]. The incidence of B cell lymphoma in the HCV transgenic mouse strain (MxCre/ CN2-29) is high, and this strongly suggests that development of $\mathrm{B}$ cell lymphomas occurs via expression of the $\mathrm{HCV}$ transgene.

Recent findings indicate a link between sIL-2R $\alpha$ levels and hepatocellular carcinoma in Egyptian patients [21]. The level of IL-2R $\alpha$ was higher in splenocytes of RzCD19Cre mice than in those of CD19Cre mice; however, the differences in the serum concentrations of sIL-2R $\alpha$ between RzCD19Cre mice without B cell lymphomas and other control groups (Rz, CD19Cre, and WT) were insignificant. These results indicate that HCV increases IL-2R $\alpha$ expression in B cells; proteolytic cleavage of IL-2R $\alpha$ increased after B cell lymphoma development in the RzCD19Cre mice. The detailed mechanism by which HCV expression induces IL- $2 \mathrm{R} \alpha$ remains unclear, but HCV core protein induces IL-10 expression in mouse splenocytes [12]. IL-10 upregulates the expression of IL-2R $\alpha$ (Tac/CD25) in normal and leukemic B lymphocytes [22]. Therefore, through IL-10, the HCV core protein might induce IL-2R $\alpha$ in B cells of the RzCD19Cre mouse.

Disruption of irf- 1 enables the persistent expression of HCV protein. This leads to lymphoproliferative diseases resulting from reduced apoptosis (i.e., lower levels of caspase-1, caspase-6, and caspase-7 expression). HCV CN2 transgenic $(\mathrm{Tg}+)$ mice are resistant to Fas-induced apoptosis because of the inhibition of cytochrome $c$ release from mitochondria [11]. Mice with disruption of irf-1 have several defects in their innate and adaptive immunities, including lineagespecific defects in thymocyte development, and the development of immature $\mathrm{T}$ cells into mature $\mathrm{CD} 4^{+}$cells but not $\mathrm{CD}^{+} \mathrm{T}$ cells $[16,23]$. IRF-1 controls the positive and negative selection of $\mathrm{CD} 8^{+}$thymocytes [24] and is required for the development of the Th1-type immune response. The absence of IRF-1 induces Th2-type immune response
$[16,25]$. The number of natural killer cells is dramatically reduced in $\mathrm{irf}-1^{-/-}$mice [16]. This defect may markedly increase viral protein expression and inhibit tumor surveillance mechanisms, leading to the development of nonHodgkin lymphoma. Expression of the IL-12 p40 subunit is defective in $\operatorname{irf-1^{-/-}}$ mice [16].

Hypermutation of the immunoglobulin genes in B cells induced by HCV infection is the cause of the lymphomagenesis observed in HCV infection [16, 26]. This finding may provide a more direct insight into lymphoma production, because $\mathrm{HCV}$-induced hypermutation causes genetic instability and chromosomal aberrations, possibly resulting in neoplastic transformation [27]. In addition, the antiapoptotic phenotype resulting from sustained viral protein expression may enhance the survival of lymphocytes and inhibit activation-induced cell death to turn off the activated lymphocytes. The dysregulated cytokine profiles and sustained lymphocyte survival may alter the fates of regulatory T cells and dendritic cells [28].

In summary, the mouse model of B cell lymphoma and lymphoproliferative disorder represents a powerful tool to address the molecular mechanism of lymphoma development by HCV.

\section{Conflict of Interests}

The authors declare that there is no conflict of interests.

\section{Acknowledgments}

This work was supported by grants from the Ministry of Health and Welfare of Japan and the Cooperative Research Project on Clinical and Epidemiological Studies of Emerging and Re-emerging Infectious Diseases. The authors thank Drs. M. Saito, K. Kuwahara, N. Sakaguchi, M. Takeya, Y. Hiasa, S. Harada, and A. El-Gohary for their valuable collaborations.

\section{References}

[1] J. Ferlay, F. Bray, P. Pisani, and D. M. Parkin, Globocan 2000: cancer incidence, mortality and prevalence worldwide. version1.0. IARC CancerBase No. 5. IARC, Lyon, France, 2001.

[2] F. Dammacco, D. Sansonno, C. Piccoli, V. Racanelli, F. P. D'Amore, and G. Lauletta, "The lymphoid system in hepatitis C virus infection: autoimmunity, mixed cryoglobulinemia, and overt B-cell malignancy," Seminars in Liver Disease, vol. 20, no. 2, pp. 143-157, 2000.

[3] J. P. Gisbert, L. García-Buey, M. J. Pajares, and R. MorenoOtero, "Prevalence of hepatitis $\mathrm{C}$ virus infection in B-cell nonHodgkin's lymphoma: systematic, review and meta-analysis," Gastroenterology, vol. 125, no. 6, pp. 1723-1732, 2003.

[4] P. Pileri, Y. Uematsu, S. Campagnoli et al., "Binding of hepatitis C virus to CD81," Science, vol. 282, no. 5390, pp. 938-941, 1998.

[5] D. Rosa, G. Saletti, E. De Gregorio et al., "Activation of naïve B lymphocytes via CD81, a pathogenetic mechanism for hepatitis C virus-associated B lymphocyte disorders," Proceedings of the National Academy of Sciences of the United States of America, vol. 102, no. 51, pp. 18544-18549, 2005. 
[6] H. Lerat, S. Rumin, F. Habersetzer et al., "In vivo tropism of hepatitis $\mathrm{C}$ virus genomic sequences in hematopoietic cells: influence of viral load, viral genotype, and cell phenotype," Blood, vol. 91, no. 10, pp. 3841-3849, 1998.

[7] S. J. Karavattathayyil, G. Kalkeri, H. J. Liu et al., "Detection of hepatitis $\mathrm{C}$ virus RNA sequences in B-cell non-Hodgkin lymphoma," American Journal of Clinical Pathology, vol. 113, no. 3, pp. 391-398, 2000.

[8] Y. Kasama, S. Sekiguchi, M. Saito et al., "Persistent expression of the full genome of hepatitis $\mathrm{C}$ virus in B cells induces spontaneous development of B-cell lymphomas in vivo," Blood, vol. 116, no. 23, pp. 4926-4933, 2010.

[9] R. C. Rickert, J. Roes, and K. Rajewsky, "B lymphocytespecific, Cre-mediated mutagenesis in mice," Nucleic Acids Research, vol. 25, no. 6, pp. 1317-1318, 1997.

[10] T. Wakita, C. Taya, A. Katsume et al., "Efficient conditional transgene expression in hepatitis $\mathrm{C}$ virus cDNA transgenic mice mediated by the Cre/loxP system," The Journal of Biological Chemistry, vol. 273, no. 15, pp. 9001-9006, 1998.

[11] K. Machida, K. Tsukiyama-Kohara, E. Seike et al., "Inhibition of cytochrome $\mathrm{c}$ release in fas-mediated signaling pathway in transgenic mice induced to express hepatitis C viral proteins," The Journal of Biological Chemistry, vol. 276, no. 15, pp. 12140-12146, 2001.

[12] K. Machida, K. Tsukiyama-Kohara, S. Sekiguch et al., "Hepatitis $\mathrm{C}$ virus and disrupted interferon signaling promote lymphoproliferation via type II CD95 and interleukins," Gastroenterology, vol. 137, no. 1, pp. 285-296, 2009.

[13] K. Moriya, H. Fujie, Y. Shintani et al., "The core protein of hepatitis $\mathrm{C}$ virus induces hepatocellular carcinoma in transgenic mice," Nature Medicine, vol. 4, no. 9, pp. 1065-1067, 1998.

[14] H. Lerat, M. Honda, M. R. Beard et al., "Steatosis and liver cancer in transgenic mice expressing the structural and nonstructural proteins of hepatitis C virus," Gastroenterology, vol. 122, no. 2, pp. 352-365, 2002.

[15] T. Yokota, K. Oritani, I. Takahashi et al., "Adiponectin, a new member of the family of soluble defense collagens, negatively regulates the growth of myelomonocytic progenitors and the functions of macrophages," Blood, vol. 96, no. 5, pp. 17231732, 2000.

[16] S. Taki, T. Sato, K. Ogasawara et al., "Multistage regulation of Th1-type immune responses by the transcription factor IRF1," Immunity, vol. 6, no. 6, pp. 673-679, 1997.

[17] D. Hockenbery, G. Nunez, C. Milliman, R. D. Schreiber, and S. J. Korsmeyer, "Bcl-2 is an inner mitochondrial membrane protein that blocks programmed cell death," Nature, vol. 348, no. 6299, pp. 334-336, 1990.

[18] J. C. Reed, M. Cuddy, T. Slabiak, C. M. Croce, and P. C. Nowell, "Oncogenic potential of bcl-2 demonstrated by gene transfer," Nature, vol. 336, no. 6196, pp. 259-261, 1988.

[19] Y. Tsujimoto, L. R. Finger, and J. Yunis, "Cloning of the chromosome breakpoint of neoplastic B cells with the $t(14 ; 18)$ chromosome translocation," Science, vol. 226, no. 4678, pp. 1097-1099, 1984.

[20] Y. Kawamura, K. Ikeda, Y. Arase et al., "Viral elimination reduces incidence of malignant lymphoma in patients with hepatitis C," American Journal of Medicine, vol. 120, no. 12, pp. 1034-1041, 2007.

[21] A.-R. N. Zekri, H. M. A. El-Din, A. A. Bahnassy et al., "Serum levels of soluble Fas, soluble tumor necrosis factor-receptor II, interleukin-2 receptor and interleukin-8 as early predictors of hepatocellular carcinoma in Egyptian patients with hepatitis C virus genotype-4," Comparative Hepatology, vol. 9, article 1, 2010.
[22] A. C. Fluckiger, P. Garrone, I. Durand, J. P. Galizzi, and J. Banchereau, "Interleukin 10 (IL-10) upregulates functional high affinity IL-2 receptors on normal and leukemic B lymphocytes," Journal of Experimental Medicine, vol. 178, no. 5, pp. 1473-1481, 1993.

[23] T. Taniguchi, K. Ogasawara, A. Takaoka, and N. Tanaka, "IRF family of transcription factors as regulators of host defense," Annual Review of Immunology, vol. 19, pp. 623-655, 2001.

[24] J. M. Penninger, C. Sirard, H.-W. Mittrücker et al., "The interferon regulatory transcription factor IRF-1 controls positive and negative selection of CD8+ thymocytes," Immunity, vol. 7, no. 2, pp. 243-254, 1997.

[25] M. Lohoff, D. Ferrick, H.-W. Mittrücker et al., "Interferon regulatory factor- 1 is required for a T helper 1 immune response in vivo," Immunity, vol. 6, no. 6, pp. 681-689, 1997.

[26] K. Machida, K. T.-N. Cheng, V. M.-H. Sung et al., "Hepatitis $\mathrm{C}$ virus induces a mutator phenotype: enhanced mutations of immunoglobulin and protooncogenes," Proceedings of the National Academy of Sciences of the United States of America, vol. 101, no. 12, pp. 4262-4267, 2004.

[27] K. Machida, Y. Kondo, J. Y. Huang et al., "Hepatitis C virus (HCV)-induced immunoglobulin hypermutation reduces the affinity and neutralizing activities of antibodies against HCV envelope protein," Journal of Virology, vol. 82, no. 13, pp. 6711-6720, 2008.

[28] A. Dolganiuc, E. Paek, K. Kodys, J. Thomas, and G. Szabo, "Myeloid dendritic cells of patients with chronic HCV infection induce proliferation of regulatory T lymphocytes," Gastroenterology, vol. 135, no. 6, pp. 2119-2127, 2008. 


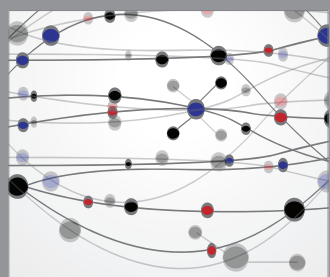

The Scientific World Journal
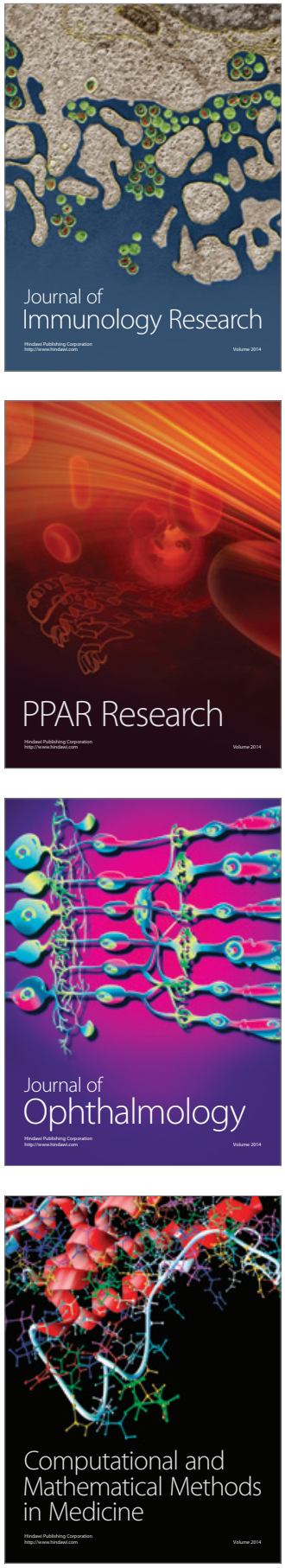

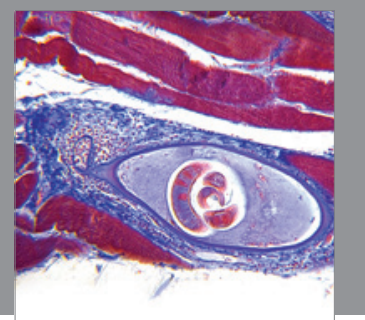

Gastroenterology

Research and Practice
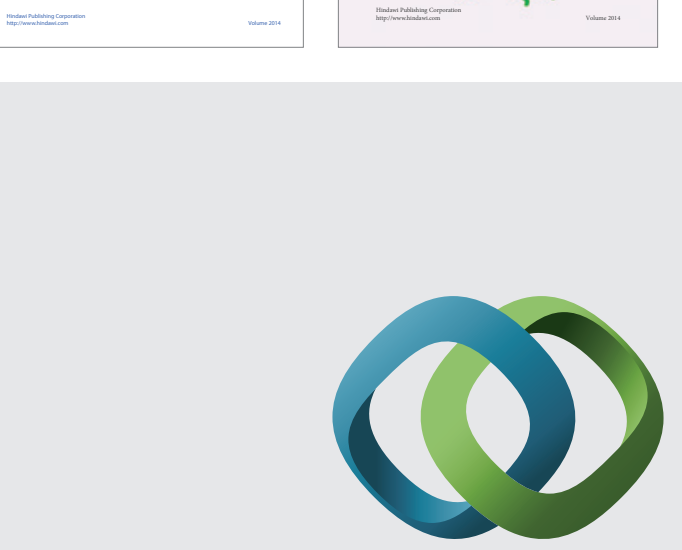

\section{Hindawi}

Submit your manuscripts at

http://www.hindawi.com
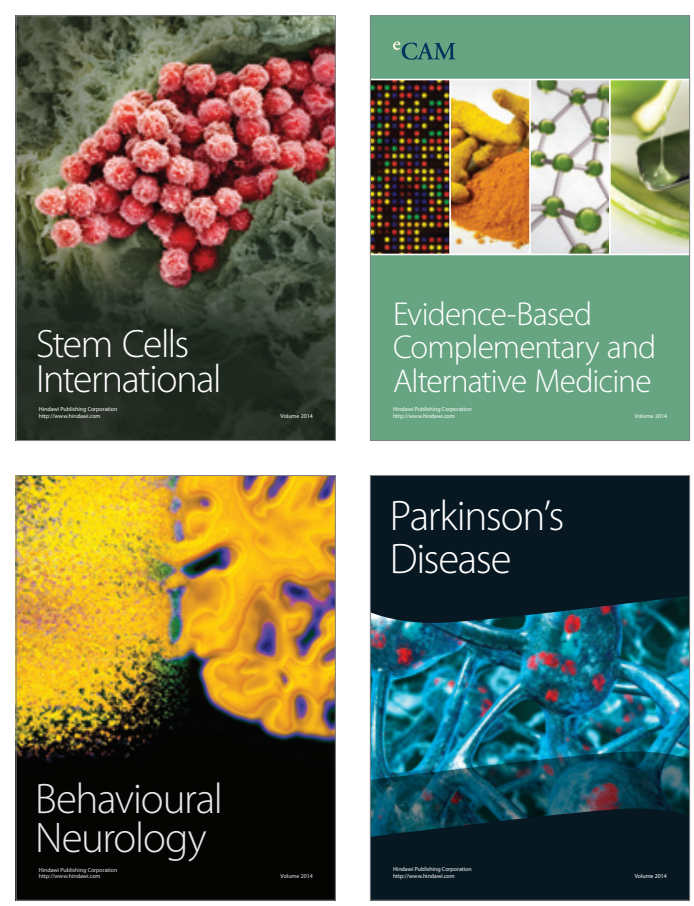

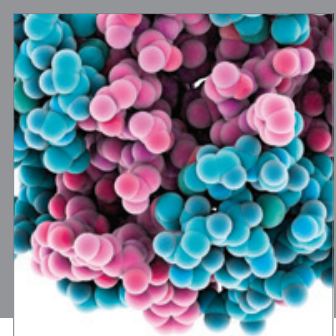

Journal of
Diabetes Research

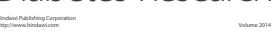

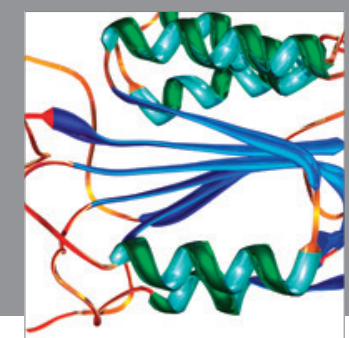

Disease Markers
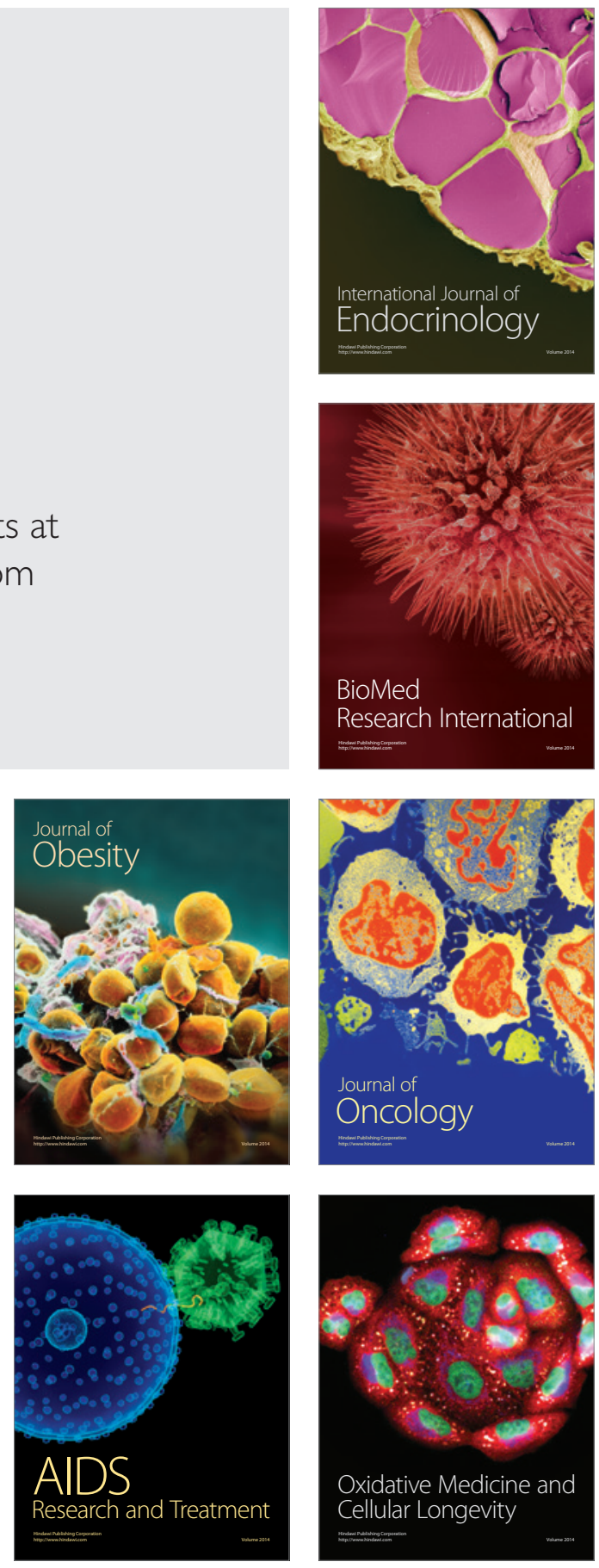